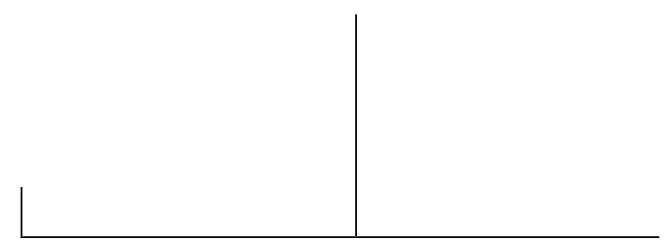

Rev. Latinoam. Psicopat. Fund., São Paulo, v. 12, n. 2, p. 342-355, junho 2009

\title{
A transferência como articuladora entre a clínica e a política nos serviços de atenção psicossocial*
}

Daniela Santos Bezerra

Doris Luz Rinaldi

Este trabalho visa analisar as questões que surgiram no cotidiano de serviços de atenção psicossocial, evidenciando a importância do manejo da relação entre técnicos, usuários e familiares na efetivação da clínica oferecida. A partir de exemplos clínicos e utilizando o conceito de transferência como contribuição da clínica psicanalítica à clínica ampliada, propõe-se a inclusão do sujeito do inconsciente como fundamental ao processo de Reforma Psiquiátrica, já que este sujeito, que difere do cidadão de direitos, é radicalmente responsável por sua posição.

Palavras-chave: Psicanálise, transferência, atenção psicossocial; clínica ampliada

* Este artigo resulta da extração de algumas reflexões elaboradas na dissertação "O lugar da clínica na Reforma Psiquiátrica Brasileira" de Daniela Santos Bezerra, orientada pela Profa. Dra. Doris Luz Rinaldi, como exigência para a conclusão do Mestrado em Pesquisa e Clínica em Psicanálise, do Programa de Pós-Graduação em Psicanálise (PGPSA) do Instituto de Psicologia da Universidade do Estado do Rio de Janeiro IP/UERJ (Rio de Janeiro, RJ, Brasil). A pesquisa realizada é parte integrante do projeto da pesquisa: "Clínica do sujeito e atenção psicossocial: novos dispositivos de cuidado no campo da saúde mental", desenvolvida no Instituto de Psicologia da Universidade do Estado do Rio de Janeiro desde outubro de 2003 e coordenado pela Profa. Dra. Doris Luz Rinaldi. Foi realizada junto à equipe de profissionais da Ala de Internação Masculina do CIAPS Adauto Botelho, sob aprovação do Comitê de Ética de Pesquisa com Seres Humanos da Escola de Saúde Pública da Secretaria do Estado de Saúde de Mato Grosso (Cuiabá, MT, Brasil). 


\section{SAÚDE MENTAL}

Uma paciente chama pela psicóloga que a atende no Centro de Atenção Psicossocial (CAPS) durante sua observação no Pronto atendimento do hospital psiquiátrico, sem encontrar resposta. Um paciente ex-egresso da internação prefere voltar ao pronto atendimento do hospital psiquiátrico frequentemente a se vincular a um serviço substitutivo porque lá, segundo ele, "só há trabalhinhos para mulheres". Uma mulher quase é desligada de seu tratamento em um hospital-dia depois de seis meses de tratamento, porque revelou uma estrutura neurótica estabilizada, o que levou o psiquiatra a alterar o seu diagnóstico. De acordo com a portaria n. 189/2001 do Ministério da Saúde (Brasil, 2002, p. 39), com este novo diagnóstico a usuária deveria ser atendida em ambulatório, pois, ao manter-se o atendimento no hospital-dia, haveria o risco de que o Ministério da Saúde não efetuasse o repasse da verba destinada aos "procedimentos de alta complexidade" para esta unidade. Um senhor de sessenta e poucos anos, "morador" do hospital psiquiátrico, que não fala, passa a falar e xingar, agarrado a um saco de roupas sujas feito por ele, quando percebe o movimento do Serviço Social em ressocializá-lo, enviando-o a uma residência terapêutica.

O que tais situações têm em comum? Onde buscar respostas a tais impasses do cotidiano dos serviços de atenção psicossocial brasileiros? Estas e muitas outras questões surgidas no dia a dia do Complexo Integrado de Atenção Psicossocial Adauto Botelho de Cuiabá, Mato Grosso, é que nos levaram à reflexão quanto ao processo de mudanças implantadas pela Reforma Psiquiátrica no Brasil, no que tange à condução da clínica destes serviços. A partir de nossa inserção nos serviços de saúde mental, percebemos que tais questões não se restringem somente aos serviços do Estado de Mato Grosso, mas sim são questões relativas à saúde mental pública em todo o Brasil.

O questionamento da lógica manicomial efetuado pela Reforma Psiquiátrica trouxe consigo a crítica ao modelo tradicional da clínica psiquiátrica. Apostando que o paradigma desta clínica seria sinônimo de rotulação, medicalização e segregação, muitas discussões colocadas pelos idealizadores da Reforma Psiquiátrica colocaram a clínica em xeque, ou mesmo, em segundo plano (Bezerra, 2008), o que se percebe no cotidiano dos serviços.

A crítica à clínica tradicional também passou pela crítica à exclusão ao sujeito, operada pela lógica manicomial, porém percebemos que as próprias mudanças na assistência que propõem colocar o usuário como protagonista de seu tratamento (Ministério da Saúde, 2002, p. 18) muitas vezes vêm desconsiderando a implicação do sujeito em seu sofrimento, bem como ignorando 


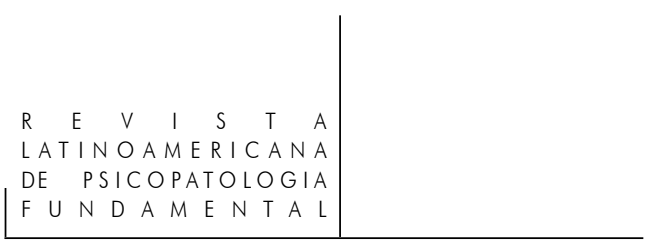

a relação - fundamental à clínica - entre técnicos e usuários. Percebemos em nossa pesquisa que muitas ações das equipes - à primeira vista inovadoras - mantêm o usuário de saúde mental, de modo subjacente, na condição de "alienado". No novo campo de atenção psicossocial, o que restou de clínico é dimensionado a partir de diretrizes de ressocialização e de aquisição de uma cidadania legalizada, porém não efetivada pela sociedade. Muitos dos impasses ocorridos no cotidiano dos serviços tornam-se pontos cegos na assistência, por não se levar em conta uma dimensão fundamental, ressaltada pela psicanálise, que é a dimensão inconsciente, em que o sujeito, ao contrário do que poderia parecer, é considerado como radicalmente responsável pela sua posição (Lacan, 1956, p. 873). Muitas vezes este sujeito se apresenta como excesso para a equipe que trabalha focalizando exclusivamente os seus direitos de cidadão (Rinaldi, 2005, p. 93). Essas duas dimensões - sujeito do inconsciente e cidadania -, apesar de heterogêneas, não são, contudo, opostas. Para se pensar a questão dos direitos deve-se levar em conta, em primeiro lugar, a implicação do sujeito nesta questão, o que pressupõe a sua posição frente ao Outro (p. 95). Isso nos faz concluir que clínica e política em saúde mental podem ser articuladas.

Estas são as questões que buscamos analisar, trazendo à discussão contribuições da psicanálise para a prática dos serviços de atenção psicossocial.

A Reforma Psiquiátrica, ao implantar políticas públicas para realizar a chamada substituição ao manicômio, operou uma ampliação em duas vias. A primeira voltou-se para a ampliação da atenção ao usuário de saúde mental, ou seja, ampliação da clínica com a implantação de recursos e dispositivos alternativos que envolvem não somente o tratamento médico, mas também aspectos da vida social do usuário como esporte, lazer e cultura. A nova clínica, denominada de "clínica ampliada", difere da clínica psiquiátrica tradicional por estar aberta a novos saberes, incluindo, no foco do tratamento, toda gama de aspectos da vida do usuário implicada em sua posição de sofrimento. Isto implica, para além do alívio dos sintomas, orientação à família, suporte social, criação de alternativas de trabalho, moradia e lazer, garantia de direitos, dentre outras ações. Por isso mesmo a mudança de nomenclatura de "saúde mental" para "rede de atenção psicossocial" (Delgado, 1997, p. 47). É importante enfatizar que, mais recentemente, vemos a inclusão também do trabalho com o sujeito do inconsciente, dada a inserção de psicanalistas no cotidiano de alguns serviços.

A segunda via de ampliação constitui-se na redistribuição das funções dos serviços, ou seja, a responsabilidade pela atenção psicossocial passa a ser atribuída a diversos tipos de serviços, em diversas localidades dentro dos municípios. Esta ampliação contrapõe-se à lógica manicomial, que definiu que, na maior parte do Brasil, os hospitais psiquiátricos ou "colônias para loucos" fossem construídos 


\section{SAÚDE MENTAL}

fora da cidade, fora do espaço público. A partir desta redistribuição, o hospital psiquiátrico ou a internação psiquiátrica deixa de exercer o papel principal dentro da rede de atenção psicossocial. Mais ainda, toda a rede do Sistema Único de Saúde é convocada a acolher os usuários de saúde mental em suas diferentes demandas e situações, sendo elas relativas especificamente ao seu sofrimento psíquico ou não. O mesmo usuário de saúde mental pode ser atendido, por causa de seu sofrimento psíquico, em várias modalidades de serviço: desde os CAPS até os hospitais gerais. Há, deste modo, uma gama de diferentes ofertas de tratamento possíveis e demandadas, dependendo do que se apresenta como manifestação de um sofrimento e dos cuidados que essa manifestação exige naquele determinado momento. Tais ofertas se configuram, além da internação, como o atendimento multidisciplinar de alta complexidade (realizado nos CAPS), o atendimento em ambulatórios, bem como o acompanhamento pelos técnicos dos Programas Saúde da Família (PSFs) e Programas de Agentes Comunitários (PACs) e as campanhas e eventos sociais que levam a nova política de atenção psicossocial à sociedade em geral.

Segundo Pedro Gabriel Delgado (1997), no início - final da década de 1990 - as mudanças implantadas na saúde mental pública tinham como principal intuito mudar a lógica de descontinuidade do tratamento ambulatorial que ocorria no pós-alta hospitalar (p. 47). Assim, a proposta da Reforma Psiquiátrica Brasileira vem sendo a de tornar a atenção psicossocial uma ação a ser realizada fora do hospital, enquanto instituição fechada: no espaço público, nos bairros, junto à família e à comunidade. Deste modo, iniciou-se uma rede de serviços de base territorial.

A noção de território está referenciada na Psiquiatria Democrática Italiana, bem como na Psiquiatria de Setor francesa e na Psiquiatria de Preventiva norteamericana. Nas palavras de Delgado, a literatura norte-americana distingue os serviços como sendo de "base hospitalar" e os de "base comunitária". No Brasil, o termo comunitária "faz lembrar, inevitavelmente, as ideias preventivistas: intervir na comunidade, identificar situações de maior risco, prevenir o aparecimento de transtornos" (p. 42). Por este motivo é que o autor considera que o conceito de território, originado na Psiquiatria Democrática italiana, é mais próximo das diretrizes da Reforma Psiquiátrica Brasileira.

Deste modo, teoricamente, a noção de território é tomada, no Brasil, para além do campo da Geografia, incluindo nela tudo o que está fora da noção de instituição. De acordo com Delgado, a partir desta lógica, o território é aquilo que se circunscreve, por meio de contornos subjetivos, à referência cultural, familiar, mitológica, socioeconômica de cada usuário de saúde mental. Para este autor, tal processo de mudanças é um desafio teórico com grandes implicações clínicas (p. 42). Percebemos a veracidade desta afirmação em nossa prática, prin- 


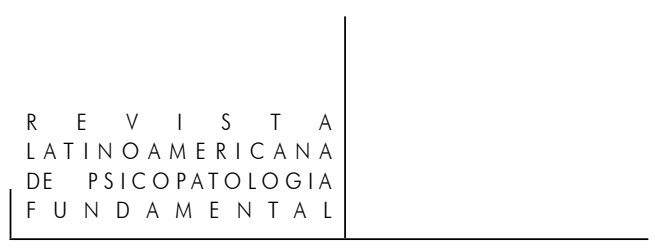

cipalmente quando a noção de território não é utilizada como espaço de referência subjetiva. Em sua aplicação, a noção de território se perde em uma dimensão geo ou demográfica, causando efeitos enviesados no que tange à referência e ao vínculo dos usuários junto aos serviços, somente trocando o problema da cronificação dos usuários de lugar: do hospital para um ciclo vicioso dentro da rede.

Os próprios técnicos implicados, uns mais e outros menos, no possível desarranjo do processo de mudança encontram dificuldades para lidar com a nova lógica e parecem buscar na literalidade da lei um norte para seguir. A rede de atenção psicossocial acaba, assim, por priorizar a distribuição de usuários de acordo com seus endereços domiciliares, não considerando o vínculo estabelecido entre os usuários e os serviços e técnicos aos quais estavam até então referenciados.

Tal problemática não se refere simplesmente à saída do usuário do manicômio para que ele seja tratado próximo à sua casa, junto aos seus. Trata-se da complexidade da clínica praticada em toda nova rede de atenção. Como exemplo, citamos a destituição do ambulatório de saúde mental de Cuiabá, que fez com que os técnicos (psiquiatras e psicólogos concentrados num só prédio) fossem redistribuídos pelas chamadas Policlínicas da capital; porém, nem sempre o bairro onde determinado técnico passou a exercer suas funções corresponde ao bairro onde vive determinado usuário que possui vínculo estabelecido com o referido técnico. Muitos usuários voltaram a um ciclo de internações psiquiátricas, após um longo período de estabilização, relatando estarem perdidos na nova rede de atenção.

Quando questionamos a clínica praticada na rede de atenção psicossocial não estamos com isso negligenciando as questões políticas e necessidade de aquisição de direitos dos usuários implicadas no tratamento oferecido. Discutir a clínica é justamente colocar em prática as diretrizes da Reforma Psiquiátrica, pelo viés do sujeito.

Quando ouvimos cada um dos profissionais, encontramos uma fragilidade de sustentação das discussões sobre a clínica. Verificamos que a noção que se destaca para as equipes é a do chamado "Projeto Terapêutico". Relembrando a definição do instrutivo (Brasil, 2002, p. 16) divulgado pela Coordenação de Saúde Mental do Ministério da Saúde, pela ocasião da publicação da Portaria GM 336/02, encontramos dois modos de entender o Projeto Terapêutico. O primeiro modo diz respeito à missão institucional do serviço "dentro do âmbito de seu território". O outro modo se refere ao acompanhamento individual de cada usuário que se insere no serviço, caracterizando-se, então, como um "projeto personalizado".

Inúmeras questões surgem aí, pois o que nossa pesquisa encontrou foi a "prevalência de um discurso burocrático frente à construção de tal Projeto Te- 


\section{SAÚDE MENTAL}

rapêutico" (Rinaldi, 2007). Há uma tendência das equipes, independentemente do tipo de instituição, em constituir o Projeto Terapêutico como um roteiro a ser apresentado aos usuários, voltado para as questões de cidadania e valorização das habilidades. A proposição ministerial que fundamenta a implantação de um Projeto Terapêutico não o coloca como um documento institucional estático, mas sugere que ele deve servir como orientação para uma direção compartilhada de tratamento a ser redefinida caso a caso. O modo como ele vem sendo aplicado, entretanto, lembra mais uma proteção contra os imprevistos, em que é o usuário quem deve adaptar-se ao Projeto Terapêutico e não o tratamento ser constituído a partir da relação que o sujeito em causa estabelece com o serviço. Isso burocratiza o Projeto Terapêutico, direcionando-o muito mais às questões legais do que propriamente clínicas.

Desta forma, perde-se, inclusive, a oportunidade de tomar a importância da função do Técnico de Referência, outra noção introduzida pela Clínica Ampliada, no tratamento oferecido nos serviços. A função do Técnico de Referência é a de ter em vista, a partir de cada intervenção feita, a totalidade do andamento do caso, sendo o articulador da relação entre usuário, família e serviço. Mas nem sempre vemos que os Técnicos de Referência são aqueles eleitos pelos usuários dentre os técnicos do serviço como referência de tratamento. A designação deste técnico também acaba ocorrendo de forma burocrática e não baseada na relação entre usuários e técnicos.

\section{A transferência na Clínica Ampliada}

Para tentar avançar a discussão que se situa na intersecção da clínica e da política de atenção psicossocial no Brasil, valemo-nos do conceito psicanalítico de transferência.

As mudanças trazidas pela Reforma Psiquiátrica, com a ampliação e reconfiguração da clínica, abriram novas possibilidades de estabelecimento de laços para os usuários de saúde mental e seus familiares. De fato, em contraste com o contexto manicomial anterior, excludente e homogeneizante, é possível perceber que, depois de quinze anos de Reforma, os usuários encontram nos novos dispositivos de tratamento dos serviços de saúde mental uma diversidade de caminhos para a sua reinserção na comunidade. Mas, se levamos em conta o Inconsciente, sabemos que as diversificações cotidianas não garantem que haja uma mudança estrutural nas relações possíveis de um sujeito. É neste sentido que vemos a importância do campo transferencial, pois é nele que as relações se estruturam e podem ser trabalhadas clinicamente. 


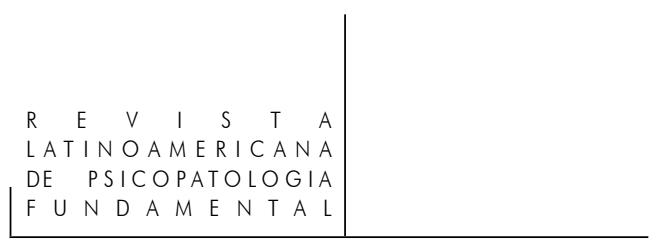

A transferência surgiu para Freud (1914) como um impasse, exigindo que ele elaborasse um modo específico de manejá-lo para que o tratamento psicanalítico se efetivasse. Ele se apercebeu de que tal impasse, paradoxalmente, tem as mesmas origens que os afetos que impulsionam o tratamento. Assim, a transferência é, ao mesmo tempo, impasse e mola propulsora do tratamento. Foi justamente por causa da emergência do sujeito e dos impasses que isso causou à clínica médica que a psicanálise nasceu. Dito de outro modo, a psicanálise começou a ser elaborada a partir de algo do paciente que insistia em atrapalhar ou surpreender a Freud, que seguia os passos ditados pela Medicina de sua época.

Freud demonstrou que a transferência também ocorre nas instituições e fora do tratamento psicanalítico. Pode, inclusive, assumir, como diz ele, formas as mais indignas de "servidão mental" (p. 136). A novidade trazida por ele foi justamente a de descobrir as suas raízes inconscientes e fazer deste fenômeno o operador central da clínica. A transferência se desenvolve a partir da inclusão na realidade psíquica do sujeito do novo campo de relações estabelecidas com o psicanalista, o que pressupõe um reinvestimento pulsional. Sua importância é tão fundamental à clínica que Freud (1912b) instituiu que o tratamento só é possível a partir de instalada a transferência.

Trazendo este conceito ao cotidiano dos serviços de atenção psicossocial, a relação entre usuário e os técnicos passa a fazer parte dos problemas e soluções encontrados por cada usuário. Contudo, a transferência não se estabelece a partir da mesma lógica instituída pela realidade dos serviços, mas sim como efeito do Inconsciente, que não necessariamente está em conformidade com a realidade delineada pelo cotidiano dos serviços. Este impasse clínico na maioria das vezes não é tratado pela equipe dos serviços e trabalhado em sua importância, fato que traz inúmeros problemas para a realização da clínica na saúde mental pública. Sua importância exigiria que esta clínica estivesse mais voltada à singularidade dos casos e menos ao seguimento generalizante e burocrático de portarias ministeriais. Aí se coloca novamente a necessidade de se levar em conta quem o usuário inconscientemente elegeu como sua própria referência de tratamento, pois é somente a partir desta eleição, como pivô do tratamento, que as intervenções do serviço poderão surtir efeito.

Trata-se aqui de reforçar a própria diretriz do Projeto Terapêutico Singular, ${ }^{1}$ pela qual os técnicos devem estar em constante questionamento de suas ações,

1. Cartilha do Ministério da Saúde: Clínica Ampliada, Técnico de Referência e Projeto Terapêutico Singular. 2. ed. Site do Ministério da Saúde. Núcleo Técnico da Política Nacional de Humanização. Brasília, 2007 <bvsms.saude.gov.br/bvs/publicacoes/clinica_ampliada.pdf > 


\section{SAÚDE MENTAL}

levando em conta a singularidade dos casos e não ensurdecidos pela literalidade legal. A ideia de território, por exemplo, deve ser tomada de modo subjetivado, avaliada a partir de cada caso, pois, ao seguir uma rigidez geográfica ou demográfica, ela somente estará trocando o problema da cronificação dos usuários de lugar: do hospital para um ciclo vicioso dentro da rede.

No caso paradigmático da usuária quase desligada de seu tratamento no hospital-dia, graças a várias discussões em equipe, a mesma continuou no serviço. Concluiu-se que foi por causa da transferência estabelecida com aqueles técnicos que ela tinha podido restituir-se, sair de seu momento de sofrimento agudo, reconhecer-se como sujeito de seu próprio tratamento e queria seguir tratando-se ali.

Neste sentido é importante reconhecer o que a psicanálise introduz de novidade diante de uma clínica puramente terapêutica. A etimologia do termo terapia designa cuidado ou tratamento que visa ao restabelecimento do bem-estar. Desde o início de sua obra, Freud (1905) colocou em questão o tratamento pela via da terapia, que, segundo ele, utiliza técnicas conhecidas pela Medicina desde a Antiguidade: a sugestão e a persuasão. Desde seus primórdios a Medicina fez uso de técnicas de sugestão e persuasão que consistiam em influenciar o paciente, por meio de um saber atribuído ao médico. Segundo Jacques Lacan (19601961, p. 262), esta atribuição ou amor dirigido ao saber do médico ou do analista, ou, no nosso caso, a qualquer um dos técnicos da equipe, é o cerne do processo de transferência, que na clínica deve ser manejada para, em vez de influenciar o paciente, promover o tratamento, partindo principalmente da não correspondência destes afetos. Encontramos uma importante recomendação freudiana quanto à vontade de ajudar e fazer o bem ao paciente: a de que, como profissional, é preciso guiar-se pelas capacidades do paciente em vez de por seus próprios desejos (Freud, 1912b).

Ao discutirmos as estratégias imbuídas no Projeto Terapêutico, é importante estarmos atentos se, na tentativa de promover a cidadania dos usuários de saúde mental, não estamos caminhando pela via da sugestão, visando à promoção do bem-estar e à correspondência mútua de expectativas.

É importante nos questionarmos, como técnicos, se não estamos tentando tornar "especialmente excelente", como disse Freud no mesmo texto, um usuário a partir da aquisição de direitos, partindo da premissa de que a cidadania é um bem que ele deseja possuir. Neste caso, o Projeto Terapêutico estaria visando à cura (alvo buscado pela terapia) através da cidadania como um bem a ser alcançado por todos.

Já em 1919 Freud previu a interlocução necessária entre a psicanálise e a Saúde Mental Pública, mesmo assim insistiu em manter as mesmas recomenda- 


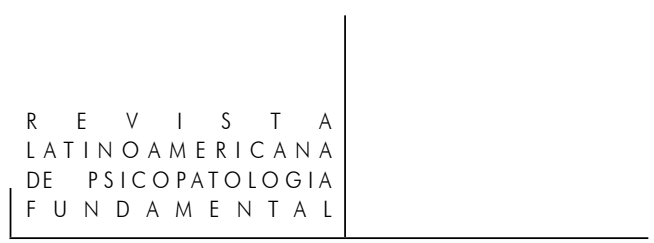

ções, uma vez que se dava conta que as instituições para "pacientes nervosos" buscavam criar um mundo tão agradável quanto possível para eles de modo a que se refugiassem das "provações da vida (Freud, 1913). Segundo ele, isso não dá suporte para que os pacientes possam "enfrentar a vida e tenham capacidade para levar a cabo as verdadeiras incumbências nela".

Trazendo esta recomendação para o serviço público, é no campo da relação transferencial que verificamos a recomendação de abstinência feita por Freud, pois se procuramos abrir espaço para o trabalho do sujeito e seu modo de estar no mundo, é importante não corresponder a uma expectativa de promoção imediata de bem-estar. Com Freud vemos que isso pode reforçar uma acomodação, calar o sujeito em vez de colocá-lo a trabalho. Assim como não nos cabe devolver a agressividade e a insatisfação lançada por usuários e familiares ou mesmo julgar o possível desinteresse destes em relação ao serviço oferecido. Levando em conta todas as questões socioeconômicas e culturais que tornam muitos usuários carentes, inclusive de formular qualquer demanda, é preciso encontrar a dosagem certa para o manejo da transferência. É neste ponto que o trabalho em equipe e a supervisão clínica - pauta também para uma outra extensa discussão - podem ajudar cada técnico na construção e na condução do caso.

Vimos também em nossa pesquisa que a saída de uma posição burocrática em relação ao Projeto Terapêutico também pode ser buscada na noção da Psicologia sobre o vínculo terapêutico, utilizada em muitos estudos das chamadas Ciências Médicas sobre a relação médico-paciente (Marques \& Arruda, 2007). Consideramos tal noção insuficiente, pois quando os técnicos levam em conta que para uma boa condução do Projeto Terapêutico o usuário de saúde mental "deve estabelecer um vínculo terapêutico" com o serviço, não parecem estar aí incluídas todas as consequências decorrentes de tal vínculo, inclusive os impasses e engodos em relação ao próprio tratamento. A partir daí podemos situar a diferença da noção de vínculo terapêutico para a noção psicanalítica de transferência, que inclui a noção da resistência. Por isso a transferência também pode ser um obstáculo ao tratamento, pois muitas vezes o sujeito, que na clínica psicanalítica é convocado ao trabalho subjetivo, para de trabalhar e passa a amar ou odiar a quem dele trata, resistindo ao tratamento (Freud,1912a).

Para situarmos tal diferença na clínica, trazemos o caso de um usuário que foi internado compulsoriamente na ala masculina do CIAPS Adauto Botelho porque ameaçou de morte o marido da assistente social do CAPS de sua cidadezinha, por ter "se apaixonado por ela". Isto fez com que tal marido, junto com os técnicos do CAPS, movessem uma ação judicial para que o usuário fosse internado, já que ele representava "um risco para a sociedade". Não corresponder à demanda amorosa do paciente não significa rechaçá-la ou incriminá-la, mas tomá-la em trabalho. Este é o desafio com o qual lida a clínica psicanalítica e com o qual os téc- 


\section{SAÚDE MENTAL}

nicos de tal CAPS não souberam lidar, ocupando mais um leito do hospital. Freud declara que no trabalho com o Inconsciente "a ambição educativa é de tão pouca utilidade quanto a ambição terapêutica" (Freud, 1912b, p. 158). Para Lacan (1958, p. 595), desde o início de seu ensino, tudo o que intervém suspendendo, destruindo ou interrompendo a continuidade do tratamento está do lado do analista. A resistência se expressa quando o analista não se atém à realidade do discurso, mas à realidade factual, empurrando o analisante para o acting out, ou seja, para a realização da transferência fora de sua presença.

A psicanálise, convocada a responder por seu modo de intervenção no âmbito do serviço público, aponta sempre para o sujeito como ponto de onde devem partir todas as ações efetuadas, invertendo a noção de que as propostas terapêuticas devem estar prontas previamente em um projeto instituído.

A vivência cotidiana da tensão entre o sujeito e a burocracia nos serviços interroga o possível enrijecimento de modelos de atendimento. Acreditamos que uma das contribuições importantes que a psicanálise pode oferecer à discussão da lógica da rede de atenção psicossocial é que se possa dar lugar ao real, à imprevisibilidade do sujeito do Inconsciente, à emergência do inesperado e à importância da transferência na condução dos casos. De acordo com Fernando Tenório (2001),

... atenção psicossocial e clínica do sujeito não são a mesma coisa. Mas uma pode tornar a outra possível - desde que a primeira evite dois riscos: o de impor ao psicótico ideais de funcionamento que são nossos e aos quais ele muitas vezes não pode corresponder, e o de acreditar que o bem-estar psicossocial torna menos relevante o trabalho subjetivo da palavra; e que a segunda reconheça os limites de qualquer prática ligada à palavra e a necessidade, em certos casos, prioridade, na psicose, de uma ajuda concreta e cotidiana ao viver. (p. 90)

Além de dar lugar produtivo ao imprevisto, tomar o sujeito como ponto de partida para as intervenções, para os encaminhamentos, para o manejo ou para a condução do caso, implica colocar em relevo a relação viva existente entre os usuários e os técnicos.

No entrecruzamento de questões consideradas como sendo de cunho político com aquelas de cunho clínico, poder-se-ia chegar a um ponto de discussão fundamental que deveria permear as ações dos técnicos de atenção psicossocial: qual o objetivo ou finalidade do tratamento? Como dar limite e não perpetuar a relação entre o usuário e a rede de atenção psicossocial? Esta constante reflexão possibilita que os serviços não se tornem eternos centros de convivência e ressocialização, nos quais a relação dos usuários com o serviço se estenderia infinitamente ou de modo difuso, reproduzindo ou repetindo as demais instituições da sociedade ou modos já existentes de laços intersubjetivos. Nossa aposta é de 


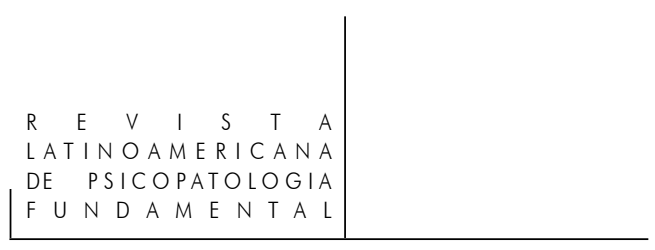

que, a partir de uma clínica ativa, a rede de serviços em saúde mental deixa de correr o risco de se tornar um conjunto de instrumentos de captura ao usuário para ser um tecido social que permita ao sujeito sua produção.

Se a Reforma Psiquiátrica no Brasil vem desconstruindo um tipo de assistência profundamente arraigada que produz, em vez de tratamento, a exclusão de cidadãos de seu meio social, a psicanálise vem propor a construção contínua de uma clínica que não tenha em seu cerne um outro tipo de exclusão: a do sujeito e seu desejo. Se pudermos ouvir as recomendações de Freud, colocando a transferência como o pilar da clínica, o sujeito passa a ter lugar na estratégia política de condução dos casos e na relação entre unidades dentro da rede. Para isso é preciso tomar o campo da transferência para além de uma conceituação teórica e o campo das leis como "vivo", fazendo parte das discussões do cotidiano. Isto implica inverter a noção aterradora de localizar no Outro (no Ministério da Saúde, na instituição, na Ordem Jurídica ou na Ordem Médica) a totalidade do saber. Implica, enfim, viabilizar uma nova política que passe pela clínica.

\section{Referências}

BRASIL/Ministério da Saúde/AS/ASTEC - Área Técnica de Saúde Mental, CAPS Nova Sistemática de cadastramento, funcionamento e registro de dados epidemiológicos - Perguntas \& Respostas - Portarias 336/02 e 189/02, Brasília, 2002.

BRASiL/Ministério da Saúde/AS/ASTEC - Núcleo Técnico da Política Nacional de Humanização Programa Humanizasus. Clínica Ampliada, Técnico de Referência e Projeto Terapêutico Singular, 2. ed. Brasília, 2007. Site do Ministério da Saúde.. Disponível em: 〈bvsms.saude.gov.br/bvs/publicacoes/clinica_ampliada.pdf > Acesso: fev. 2009.

Bezerra, D. S. O lugar da clínica na Reforma Psiquiátrica Brasileira. 2008. 126 p. Dissertação (mestrado em Pesquisa e Clínica em Psicanálise), Universidade do Estado do Rio de Janeiro - UERJ.

Birman, J.; Costa, J. F. Organização de Instituições para uma Psiquiatria Comunitária. In: Amarante, P. (Org.). Psiquiatria Social e Reforma Psiquiátrica. Rio de Janeiro: Fiocruz, 1998. p. 44-54.

Caplan, G. Princípios de psiquiatria preventiva. Rio de Janeiro: Jorge Zahar, 1980.

Delgado, P. G. A Psiquiatria no território: construindo uma rede de atenção psicossocial. FOCO - Informe Epidemiológico Saúde Coletiva, Rio de Janeiro, ano VI, n. 16, p. 41-43, 1997.

Freud, S. (1905). O tratamento psíquico ou anímico. In: Edição Standard Brasileira 


\section{SAÚDE MENTAL}

das Obras Psicológicas Completas de Sigmund Freud. Rio de Janeiro: Imago, 1976. v. XII.

. (1912a). A dinâmica da transferência. In: Edição Standard Brasileira das Obras Psicológicas Completas de Sigmund Freud. Rio de Janeiro: Imago, 1976. v. XII.

. (1912b). Recomendações aos médicos que exercem a psicanálise. In: Edição Standard Brasileira das Obras Psicológicas Completas de Sigmund Freud. Rio de Janeiro: Imago, 1976. v. VII.

(1913). Sobre o início do tratamento (Novas recomendações sobre a técnica da psicanálise I). In: Edição Standard Brasileira das Obras Psicológicas Completas de Sigmund Freud. Rio de Janeiro: Imago, 1976. v. II.

. (1914). Observações sobre o amor transferencial. In: Edição Standard

Brasileira das Obras Psicológicas Completas de Sigmund Freud. Rio de Janeiro: Imago, 1976. v. XII.

. (1919). Linhas de progresso da terapia analítica. In: Edição Standard Brasileira das Obras Psicológicas Completas de Sigmund Freud. Rio de Janeiro: Imago, 1976. v. XVII.

LaCAN, J. (1956). A ciência e a verdade. In: Escritos. Rio de Janeiro: Jorge Zahar, 1998. (1958). A direção do tratamento e os princípios de seu poder. In: Escritos. Rio de Janeiro: Jorge Zahar, 1998. Zahar, 1992.

(1960-1961). O seminário. Livro 8. A transferência. Rio de Janeiro: Jorge

Marques, C. F.; Arruda, S. L. Autismo infantil e vínculo terapêutico. Revista Virtual da PEPSIC, Campinas, v. 24, n. 1, março 2007. Disponível em: <http://www.http:// pepsic.bvs-psi.org.br/scielo>. Acesso em: ago. 2008.

Rinaldi, D. L. Relatório Final da Pesquisa: Clínica do Sujeito e Atenção Psicossocial: novos dispositivos de cuidado no campo da saúde mental - II. Rio de Janeiro, UERJ, 2007. Mimeo.

. Clínica e política: a direção do tratamento psicanalítico da saúde mental. In: Altó́, S.; Lima, M. M. (Org.). Psicanálise, clínica e instituições. Rio de Janeiro: Rios Ambiciosos, 2005.

Tenório, F. Reforma Psiquiátrica e Psicanálise: um trabalho necessário. In: FigueireDo, A. C.; Cavalcanti, M. T. (Org.). A Reforma Psiquiátrica e os desafios da desinstitucionalização - Contribuições à III Conferência Nacional de Saúde Mental. Rio de Janeiro: IPUB/CUCA, 2001. 


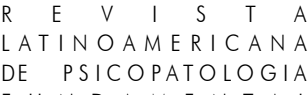

\section{Resumos}

(La transferencia como articuladora de la clínica y la política en los servicios de atención psicosocial)

Este trabajo tiene por finalidad analizar las cuestiones emergidas del cotidiano de los servicios de atención psicosocial poniendo en evidencia la importancia del manejo de la relación entre técnicos, pacientes y familiares para hacer efectiva la clínica ofrecida. Partiendo de ejemplos clínicos y utilizando el concepto de transferencia como contribución de la clínica psicoanalítica a la clínica ampliada, se propone la inclusión del sujeto del inconsciente como fundamental para el desarrollo de la Reforma Psiquiátrica, ya que ese sujeto, diferente del ciudadano de derechos, es radicalmente responsable por su posición.

Palabras claves: Psicoanálisis, transferencia, atención psicosocial, clínica ampliada

(Le transfèrement comme articulateur entre la clinique et la politique dans les services d'attention psychosocial)

Ce travail vise à analyser les questions qui surgissent dans le quotidien des services d'attention psychosocial en démontrant l'importance du maniement du rapport entre les techniciens, les utilisateurs et les membres de la famille dans l'effectuation de la clinique offerte. À partir d'exemples cliniques et en utilisant le concept de transfèrement comme contribution de la clinique psychanalytique à la clinique élargie, on propose l'inclusion du sujet de l'inconscient comme élément fondamental de la Réforme Psychiatrique, étant donné que ce sujet, qui diffère du citoyen de droits, est radicalement responsable de sa position.

Mots clés: Psychanalyse, transfèrement, attention psychosocial, clinique élargie

(Transference as articulator between the clinic and the policies at psychosocial treatment centers)

This article consists of an analysis of questions that come up in the work at a public psychosocial treatment center, and emphasizes the important issue of how to handle the relationships of technicians with users and families in establishing clinical programs for patients. The text is based on clinical examples and on the concept of transference as a contribution of psychoanalytical clinic to extended clinic. The author shows the importance of including the subject of the unconscious into the process of the reform of psychiatry in Brazil, since this subject, which differs from the concept of a subject as a citizen of rights, is fully responsible for its own position.

Key words: Psychoanalysis, transference, psychosocial treatment center, extended clinic 


\section{SAÚDE MENTAL}

Citação/Citation: BezerRa, D. S.; Rinaldi, D. L. A transferência como articuladora entre a clínica e a política nos serviços de atenção psicossocial. Revista Latinoamericana de Psicopatologia Fundamental, São Paulo, v. 12, n. 2, p. 342-355, jun. 2009.

Editor do artigo/Editor: Profa. Dra. Ana Cristina Costa de Figueiredo.

Recebido/Received: 22.3.2009 / 3.22.2009 Aceito/Accepted: 24.4.2009 / 4.24.2009

Copyright: @ 2009 Associação Universitária de Pesquisa em Psicopatologia Fundamental/ University Association for Research in Fundamental Psychopathology. Este é um artigo de livre acesso, que permite uso irrestrito, distribuição e reprodução em qualquer meio, desde que o autor e a fonte sejam citados/This is an open-access article, which permits unrestricted use, distribution, and reproduction in any medium, provided the original author and source are credited.

Financiamento/Funding: Os autores declaram não ter sido financiados ou apoiados/The authors have no support or funding to report.

Conflito de interesses: Os autores declaram que não há conflito de interesses/The authors declare that has no conflict of interest.

\section{Daniela Santos Bezerra}

Psicanalista; membro do Laço Analítico Escola de Psicanálise (Rio de Janeiro, RJ, Brasil); psicóloga da Secretaria do Estado de Saúde de Mato Grosso (Cuiabá, MT, Brasil); mestre pelo Programa de Pós-Graduação em Psicanálise do Instituto de Psicologia da Universidade Estadual do Rio de Janeiro - IP/UERJ (Rio de Janeiro, RJ, Brasil); integrante do grupo de pesquisa "Clínica do Sujeito e Atenção Psicossocial: novos dispositivos de cuidado no campo da saúde mental" pelo Programa de Pós-Graduação em Psicanálise - PGPSA entre os anos de 2006 e 2008.

Rua 62, n. 130, bloco 2, ap. 15 - Bairro Boa Esperança

78068-488 Cuiabá, MT, Brasil

Fone: (21) 2542-3793

Fone: (65) 3628-3045 / 8403-5218

e-mail: danielabezer@gmail.com

\section{Doris LuZ RinaLdi}

Psicanalista; doutora em Antropologia Social pela Universidade Federal do Rio de Janeiro UFRJ (Rio de Janeiro, RJ, Brasil); professora adjunta do Instituto de Psicologia da Universidade Estadual do Rio de Janeiro - IP/UERJ (Rio de Janeiro, RJ, Brasil); Coordenadora do Programa de Pós-Graduação em Psicanálise (PGPSA) do IP/UERJ (Rio de Janeiro, RJ, Brasil); procientista - UERJ (Rio de Janeiro, RJ, Brasil); bolsista do CNPQ; psicanalista membro da Intersecção Psicanalítica do Brasil (Recife, PE, Brasil).

Travessa Mário de Castro, 97 - Botafogo

22280-130 Rio de Janeiro, RJ, Brasil

Fone: (21) 2542-3793

e-mail: doris@uerj.br / doris_rinaldi@yahoo.com.br 